\title{
Biological interaction of cigarette smoking on the association between genetic polymorphisms involved in inflammation and the risk of lung cancer: A case-control study in Japan
}

\author{
YUZO YAMAMOTO ${ }^{1}$, CHIKAKO KIYOHARA ${ }^{2}$, SAIKO SUETSUGU-OGATA ${ }^{1}$, \\ NAOKI HAMADA $^{1}$ and YOICHI NAKANISHI ${ }^{1}$ \\ ${ }^{1}$ Research Institute for Diseases of The Chest; ${ }^{2}$ Department of Preventive Medicine, \\ Graduate School of Medical Sciences, Kyushu University, Higashi-ku, Fukuoka 812-8582, Japan
}

Received November 17, 2015; Accepted January 12, 2017

DOI: $10.3892 / \mathrm{ol} .2017 .5867$

\begin{abstract}
Chronic inflammation serves an important role in lung carcinogenesis, thus genetic polymorphisms involved in this pathway may affect the risk of lung cancer. The present case-control study focused on the association between lung cancer risk and genetic polymorphisms involved in inflammatory pathways. The study comprised 462 lung cancer cases and 379 controls from Japan. The roles of interleukin 8 (IL8) rs4073, nuclear factor kappa B $(N F \kappa B)$ rs28362491, cytochrome b-245, alpha polypeptide $(C Y B A)$ rs4673, NAD $(P)$ $H$ dehydrogenase, quinone 1 (NQO1) rs1800566, nitric oxide synthase 2 and inducible (NOS2) rs2297518 polymorphisms in lung carcinogenesis were investigated. An unconditional logistic model was used to estimate the odds ratio (OR) and 95\% confidence interval (CI) for the association between the genetic polymorphisms and lung cancer risk. The multiplicative and additive [relative excess risk due to interaction, attributable proportion due to interaction (AP) and synergy index (SI)] interactions with cigarette smoking were also determined. A significant association was revealed between the TT genotype of NQO1 rs1800566 and an increased risk of lung cancer $(\mathrm{OR}=1.78 ; 95 \% \mathrm{CI}=1.14-2.79)$. The additive interaction evaluations between $C Y B A$ rs4673 ( $\mathrm{AP}=0.50$, 95\% $\mathrm{CI}=0.15-0.85 ; \mathrm{SI}=2.66,95 \% \mathrm{CI}=1.01-6.99)$ and smoking were also statistically significant. NQO1 rs1800566 was significantly associated with lung cancer risk and smoking may influence the association between $C Y B A$ rs4673 and the risk of lung cancer. Additional studies with larger control and case populations are warranted in order to confirm the $C Y B A$ rs4673-smoking association suggested by the present study.
\end{abstract}

Correspondence to: Dr Chikako Kiyohara, Department of Preventive Medicine, Graduate School of Medical Sciences, Kyushu University, 3-1-1 Maidashi, Higashi-ku, Fukuoka 812-8582, Japan E-mail: chikako@phealth.med.kyushu-u.ac.jp

Key words: lung cancer, inflammation, polymorphism, smoking, interaction

\section{Introduction}

Lung cancer is the leading cause of cancer-associated mortality worldwide and a predominant inducing factor is exposure to cigarette smoke (1). However, fewer than one in five smokers develop lung cancer in their lifetime, while some lifelong never-smokers develop the disease (2). Therefore, inter-individual differences in susceptibility to tobacco smoke may affect lung cancer risk and some etiological factors other than tobacco smoke may contribute to disease development (3).

Accumulating epidemiological evidence supports the hypothesis that chronic inflammation serves an important role in the development and progression of various types of cancer, including lung cancer $(4,5)$. Continuous exposure to irritants, comprising cigarette smoke, induces chronic inflammatory reactions in lung tissue, DNA damage, cell proliferation and carcinogenesis (6). Smoking also increases the expression level of inflammatory mediators including interleukin 8 (IL8), in small airway epithelial cells (7). IL8 is a chemokine involved in acute and chronic inflammatory processes by activating and attracting neutrophils; thus, it may contribute to cancer development via inflammation (8). The overexpression of IL8 has been observed in various types of cancer, including lung cancer (9). IL8 has mitogenic, motogenic and angiogenic effects and, therefore, may also serve an important role in cancer progression (8). IL8 may be activated by nuclear factor kappa $\mathrm{B}(\mathrm{NF} \kappa \mathrm{B})$, which is another crucial inflammatory mediator that activates various inflammatory cytokines (10). NFאB subsequently induces chronic inflammation in lower airways and mediates carcinogenesis (11). It has previously been revealed that NFאB is frequently expressed in lung cancer (12).

Under inflammatory conditions, activated inflammatory cells serve as sources of free radicals, such as reactive oxygen species (ROS), and reactive nitrogen intermediates that induce oxidative DNA damage and genomic instability (10). ROS may be produced by NADPH oxidase (NOX) enzymes; therefore, NOX-derived ROS are a causal factor in chronic inflammation and carcinogenesis (13). Cytochrome b-245 alpha subunit $(C Y B A)$ is a subunit of the NOX family that is required for the normal functioning of NOX. CYBA is highly polymorphic and 
has been widely studied as a potential risk factor for various diseases, including malignancy (14). Functional polymorphisms of $C Y B A$ may modify the risk of cancer development by ROS generation; however only a small number of studies have reported this association to date (15). To the best of our knowledge, no previous studies have investigated the association between lung cancer risk and $C Y B A$ polymorphisms.

Nitric oxide synthase 2 (NOS2) is induced by proinflammatory cytokines, and may modify carcinogenesis by its production of high levels of NO (16). Although NO protects cells from cytotoxicity at low concentrations, it also induces DNA damage and modifies the structure and function of cancer-associated proteins at high concentrations (16), thus it is considered to initiate and promote carcinogenesis.

$\mathrm{NAD}(\mathrm{P}) \mathrm{H}$ dehydrogenase quinone 1 (NQO1) is a two-electron reductase that reduces quinones to hydroquinones in a single two-electron step (17). Benzo(a)pyrene (BP) is one of the most important carcinogens, and the formation of BP quinone-DNA adducts is prevented by NQO1 (18). By contrast, carcinogenic heterocyclic amines present in smoke are metabolically activated by NQO1 (19). Therefore, this enzyme is considered to be involved in metabolic activation and the detoxification of carcinogens. It is also plausible that NQO1 is involved in susceptibility to tobacco-associated lung carcinogenesis (20). Additionally, accumulating evidence demonstrates that NQO1 serves a role in inflammatory activities, including anti-inflammatory processes and the scavenging of superoxide anion radicals $(21,22)$.

Genetic polymorphisms involved in inflammatory pathways may affect the risk of lung cancer $(23,24)$; therefore, in the present case-control study, the association between lung cancer risk and single nucleotide polymorphisms (SNPs) known to be associated with inflammation (IL8 rs4073, $N F \kappa B$ rs28362491, NOS2 rs2297518, CYBA rs4673 and NQO1 rs1800566) were investigated within a Japanese population. Additionally, as tobacco smoke contains various carcinogens and induces chronic inflammation, the interactions between smoking and the aforementioned genetic polymorphisms were investigated. A previous study demonstrated that the combined CT and CC genotypes of CRP rs2794520 were significantly associated with an increased risk of lung cancer [odds ratio $(\mathrm{OR})=1.64 ; 95 \%$ confidence interval $(\mathrm{CI})=1.19-2.26](25)$. Furthermore, C-reactive protein (CRP) is a major indicator of inflammation, thus elevated CRP levels have been associated with an increased risk of lung cancer in a previous case-control study (26). The present study also examined the modifying effect of CRP genotypes on the association of any of the remaining polymorphisms with lung cancer risk.

\section{Materials and methods}

Study subjects and data collection. A total of 462 patients with lung cancer were registered at Kyushu University Hospital (Research Institute for Diseases of the Chest, Kyushu University, Fukuoka, Japan) and its collaborating hospitals. The 462 eligible cases were patients with primary lung cancer that was recently diagnosed and histologically confirmed during the period November 1996-March 2008. The participation rate among the cases was $100 \%$. Controls $(n=379)$ were inpatients without a clinical history of any type of malignancy, ischemic heart disease or chronic respiratory disease during the same period. Controls were not matched to cases, either individually or in larger groups, and all controls agreed to participate in this study. All subjects were unrelated ethnic Japanese. A self-administered questionnaire was used to collect data on demographic and lifestyle factors, including age, level of education, smoking and alcohol consumption. The present study was approved by the Institutional Review Board of Kyushu University Hospital. Written informed consent was obtained from all patients prior to enrollment in the present study.

Genetic analyses. Genomic DNA was extracted from blood samples using the QIAmp DNA blood Maxi kit (Qiagen Inc., Valencia, CA, USA; \#51192). Genotyping was performed blind to the case-control status using TaqMan ${ }^{\circledR}$ SNP Genotyping Assays (Applied Biosystems; Thermo Fisher Scientific, Inc., Waltham, MA, USA) for the following SNPs (gene, SNP identifier, assay ID): IL8, rs4073, C_11748116_10; CYBA, rs4673, C_2038_20; NQO1, rs1800566, C_2091255_30; NOS2, rs2297518, C_11889257_10. Genotyping of the NF $\kappa B 1-94$ ATTG insertion/deletion polymorphism (rs28362491, II; insertion/insertion, ID; insertion/deletion, DD; deletion/deletion) was performed using the polymerase chain reaction restriction fragment-length polymorphism (PCR-RFLP) method previously described by Senol Tuncay et al (27). Generally, the concordance rate between PCR-RFLP genotyping and reverse transcription-quantitative PCR assays is considered to be high (28); however, for quality control, the two assays were repeated on a random selection of $5 \%$ of all samples, resulting in $100 \%$ concordance for the replicates.

Statistical analysis. Differences (number, percentage) in selected variables, other than age or education, and genotypic frequencies between cases and controls were evaluated using the $\chi^{2}$ test. The Hardy-Weinberg equilibrium (HWE) was determined among controls for each polymorphism using the Pearson's $\chi^{2}$ test. Unconditional logistic regression was used to assess the association between genetic polymorphisms and lung cancer. ORs and the corresponding 95\% CIs were calculated by adjusting certain potential covariates (age, gender, smoking status, alcohol consumption and education). Subjects were considered to be current smokers if they smoked or had stopped smoking <one year prior to the date of diagnosis (lung cancer patients) or the date of completion of the questionnaire (controls). Non-smokers were defined as those who had never smoked in their lifetime. Former smokers were those who had stopped smoking $\geq$ one year prior to the date of diagnosis (lung cancer patients) or the date of completion of the questionnaires (controls). Ever-smokers included current and former smokers. Excessive alcohol drinkers were defined as those who drank $>20 \mathrm{~g}$ /day alcohol, based on the Healthy Japan 21 guideline, which defines an appropriate volume of alcohol intake as $20 \mathrm{~g} /$ day (29).

To assess the associations between genetic polymorphisms and smoking, multiplicative and additive interactions were determined. Multiplicative interactions were statistically evaluated based on a likelihood ratio test, comparing the models with and without interaction terms. Three evaluations for additive interaction as a departure from additivity, namely 
the relative excess risk due to interaction (RERI), attributable proportion due to interaction (AP) and synergy index (SI), were calculated by the method previously described by Andersson et al (30). RERI $>0, \mathrm{AP}>0$ or $\mathrm{SI}>1$ indicated a significant additive interaction. All statistical analyses were performed using STATA version 14 (STATA Corporation, College Station, TX, USA). The data were presented as median and interquartile range (25-75\% percentile) for age (years) and education (years) as these variables were did not have a normal distribution and they were analyzed using the Wilcoxon rank sum test. All P-values were two-sided. $\mathrm{P}<0.05$ was considered to indicate a statistically significant difference.

\section{Results}

Characteristics of study subjects. The distributions of selected characteristics among the study subjects are presented in Table I. The analysis included 462 patients with lung cancer (242 with adenocarcinoma, 131 with squamous cell carcinoma (SCC), 69 with small-cell lung carcinoma (SCLC) and 20 with large-cell lung carcinoma). Controls were not age- or gender-matched to cases; therefore, there were significant differences in age $(\mathrm{P}<0.001)$ and the gender ratio $(\mathrm{P}<0.001)$, between cases and controls. The numbers of ever-smokers and excessive drinkers were significantly higher in patients with lung cancer compared with control subjects, and patients with lung cancer were less likely to be educated compared with control subjects $(\mathrm{P}<0.001)$.

Association between genetic polymorphisms associated with inflammation and lung cancer risk. Genotypic frequencies of IL8 rs4073, NOS2 rs2297518, NF $B$ B rs28362491, CYBA rs4673 and NQO1 rs1800566 were consistent with HWE, among the controls. The frequencies and distribution of the genotypes and the ORs for lung cancer risk are presented in Table II. Minor allele frequencies (MAFs) of IL8 rs4073, $N F \kappa B$ rs28362491, NOS rs2297518, CYBA rs4673 and NQO1 rs1800566 were 32, 38, 7, 7 and 42\%, respectively. Following adjustment for age, gender, education, smoking status and alcohol consumption, the TT genotype of NQO1 rs1800566 was significantly associated with lung cancer risk $(\mathrm{OR}=1.78$; 95\% CI=1.14-2.79). Carriers of the rs1800566 $\mathrm{T}$ allele had a $42 \%$ increased risk of lung cancer $(\mathrm{OR}=1.42,95 \%$; $\mathrm{CI}=1.01-2.01)$. The remaining four polymorphisms were not associated with lung cancer risk.

Interaction between inflammation-associated polymorphisms and cigarette smoking in association with lung cancer risk. Following adjustment for age, gender, education and alcohol consumption, ever-smokers were identified to be at a higher risk of lung cancer compared with never-smokers (OR=3.17; 95\% $\mathrm{CI}=2.28-4.39$; data not presented). The allele that is presumed to increase the risk of lung cancer was described as the 'at-risk' allele. In order to achieve adequate statistical power, subjects with $\geq 1$ 'at-risk' allele were grouped together (a group termed the 'at-risk' genotype), for subsequent analysis. Ever-smokers with the 'at-risk' genotype demonstrated a higher risk of lung cancer compared with those with the non-risk genotype, relative to never-smokers with the non-risk genotype, for each of the five polymorphisms (Table III).
Following adjustment for age, gender, education and alcohol consumption, the multiplicative interactions between any of the five polymorphisms and smoking on lung cancer risk were not significant. Three additive interaction evaluations were also determined. The adjusted AP due to interaction between $C Y B A$ rs4673 and smoking was estimated to be $\sim 0.50$ $\left(95 \% \mathrm{CI}=0.15-0.85 ; \mathrm{P}_{\text {interaction }}=0.005\right)$, indicating that $50 \%$ of the excess risk for lung cancer in smokers with the CT and TT genotypes combined was due to additive interaction. Similarly, SI was 2.66 (95\% CI=1.01-6.99; $\left.\mathrm{P}_{\text {interaction }}=0.047\right)$, suggesting that the risk of lung cancer in subjects who had at least one $\mathrm{C}$ allele for $C Y B A$ rs4673 and were ever-smokers, was 2.66 times greater compared with the sum of the risk in subjects exposed to a single risk factor. No additive interactions were observed between any of the remaining four polymorphisms and smoking.

Interaction between inflammation-associated polymorphisms and the previously reported CRP rs2794520, in association with the risk of lung cancer. A previous study demonstrated that patients with $\geq 1 \mathrm{C}$ allele of $C R P$ rs2794520 were significantly associated with an increased risk of lung cancer $(\mathrm{OR}=1.64$; 95\% $\mathrm{CI}=1.19-2.26)$ (25). Regarding the five polymorphisms in the present study, subjects with $\geq 1 \mathrm{~T}$ allele of $C R P$ rs2794520 and the 'at-risk' genotype had a higher risk of lung cancer than those with the non-risk genotype, relative to subjects with the CC genotype of CRP rs2794520 and the non-risk genotype (Table IV). Following adjustment for age, gender, education, smoking history and alcohol consumption, NOX rs4673 was identified to be the only polymorphism that demonstrated an additive interaction with $C R P$ rs2794520 in association with lung cancer risk $(\mathrm{AP}=0.50 ; 95 \% \mathrm{CI}=0.10-0.89$; $\mathrm{P}_{\text {interaction }}=0.048$ ). The remaining multiplicative and additive interaction evaluations were not statistically significant.

\section{Discussion}

Accumulating evidence has demonstrated that chronic inflammation is a crucial contributing factor of cancer development at various sites (6). A number of previous epidemiological studies have also revealed that pulmonary inflammation induced by tobacco exposure, idiopathic pulmonary fibrosis, emphysema or asbestosis is associated with an increased risk of lung cancer $(5,24)$. Previous studies investigating cancer risk and genetic polymorphisms have revealed conflicting results in regard to the associations between inflammatory polymorphisms [for example, in genes encoding tumor necrosis factor $\alpha(\mathrm{TNF} \alpha)$, IL family proteins and CRP] and lung cancer risk $(25,26,31)$.

In the present study, the genotypes $I L 8$ rs $4073, N F \kappa B$ rs28362491, NOS2 rs2297518, CYBA rs4673 and NQO1 rs1800566 were determined in 462 cases of lung cancer and 379 controls. The MAFs of these polymorphisms among the controls were $0.32,0.38,0.07,0.07$ and 0.42 , respectively (Table II). This is compared with MAFs among the Japanese population of $0.27,0.37,0.08,0.07$ and 0.40 , respectively, derived from the dbSNP website (http://www.ncbi.nlm.nih. gov/SNP/). The MAF of rs4073 in the present study was higher than that of dbSNP; however, it was comparable with previous studies of Japanese populations (0.30, 0.32 and 0.33) (32-34). 
Table I. Selected characteristics of lung cancer cases and controls.

\begin{tabular}{lcrr}
\hline Characteristics & Cases (n=462) & Controls (n=379) & P-value $^{\mathrm{a}}$ \\
\hline Age (median, range) & $68(62-73)$ & $58(48-65)$ & $<0.001$ \\
Male, $\mathrm{n}(\%)$ & $287(62.1)$ & $283(74.7)$ & $<0.001$ \\
Never-smoker, $\mathrm{n}(\%)$ & $153(33.1)$ & $209(55.2)$ & $<0.001$ \\
Ever-smokerb $\mathrm{n}(\%)$ & $309(66.9)$ & $170(44.8)$ & $<0.001$ \\
Excessive drinker, $\mathrm{n}(\%)$ & $284(61.5)$ & $175(46.2)$ & $<0.001$ \\
Education (years), median (IQR) & $12(12-16)$ & & $<0.001$ \\
Histology, $\mathrm{n}(\%)$ & & & \\
Adenocarcinoma & $242(52.4)$ & \\
Squamous-cell carcinoma & $131(28.4)$ & \\
Small-cell lung carcinoma & $69(14.9)$ & \\
Large-cell lung carcinoma & $20(4.3)$ & & \\
\hline
\end{tabular}

IQR, interquartile range; ${ }^{\text {aP }}$ for $\chi^{2}$ test; ${ }^{\mathrm{b}}$ Current and former smokers were combined; ${ }^{\mathrm{c}}$ Subjects who drank $\geq 20 \mathrm{~g} / \mathrm{day}$ of alcohol. Statistical significant threshold is $\mathrm{P}<0.05$.

The genotype distributions of all polymorphisms examined in this study were consistent with HWE, among the controls.

The present study also identified that the TT genotype of NQO1 rs1800566 was significantly associated with lung cancer risk $(\mathrm{OR}=1.78 ; 95 \% \mathrm{CI}=1.14-2.79)$, whereas no significant associations were observed for the other four polymorphisms. Similarly, the NQO1 rs1800566 CT and TT genotypes combined were significantly associated with an increased risk of lung cancer $(\mathrm{OR}=1.42 ; 95 \% \mathrm{CI}=1.01-2.01)$. However, it is biologically plausible that the $N Q O 1$ polymorphisms affect lung cancer risk (20), as NQO1 has anti-carcinogenic activities, even though an association between NQO1 rs1800566 and lung cancer risk has not yet been confirmed. Notably, a recent meta-analysis study identified no significant association with lung cancer overall (35); however, stratified analysis by histology revealed that the TT and CT genotypes combined were marginally associated with an increased risk of SCC (OR for the TT and CT genotypes combined vs. the CC genotype $=1.20 ; 95 \% \mathrm{CI}=1.00-1.43 ; \mathrm{P}=0.05)$. In the present study, stratified analysis by histological group indicated a significant association between SCC and the TT genotype of rs1800566 $(\mathrm{OR}=2.02$; 95\% $\mathrm{CI}=1.03-3.96 ; \mathrm{P}=0.04$; data not presented), whereas no significant association was identified in other histological groups.

The rs1800566 polymorphism (C609T, Pro187Ser) is associated with the enzymatic activity of NQO1 and has three genotypes, CC (normal enzyme activity), CT (mild activity) and TT (2-4\% of normal activity) (36). Smokers with the T allele may, therefore, be more sensitive to the effects of tobacco carcinogens such as quinones and benzene, and thus more susceptible to tobacco-associated lung cancer. The association between tobacco smoking and lung cancer has previously been revealed to be stronger for SCC and SCLC compared with adenocarcinoma (37), and may induce the association between rs1800566 and SCC. In the present study, no significant association between rs1800566 and lung cancer was demonstrated in the subgroup with SCLC; however, precise evaluation is difficult to obtain due to the small number of patients with SCLC.
In addition to the metabolism of carcinogens, accumulating evidence suggests that NQO1 may lead to lung cancer development by inflammation (20). A previous study demonstrated that inflammatory cytokines, including IL1 $\beta$ and $\mathrm{TNF} \alpha$, suppress NQO1 activity (38). Thus, under chronic inflammation, NQO1 activity may be impaired, resulting in an increased susceptibility to carcinogenesis. Additionally, NQO1 is required for stabilization of p53 (39). Under inflammatory conditions, p53 serves a crucial role in anti-carcinogenesis by mediating cell fate decisions in response to oxidative stress, including DNA damage (40). NQO1 187Ser has a short half-life compared with NQO1 187Pro (41); therefore, p53 may be unstable in the presence of NQO1 187Ser. Loss of NQO1 function is associated with increased pulmonary oxidative stress (22), thus it is plausible that individuals carrying the T allele of NQO1 rs1800566 may be more susceptible to inflammation-associated lung carcinogenesis.

The present study revealed no significant associations between lung cancer risk and the remaining four polymorphisms (IL8 rs4073, NFKB rs28362491, NOS2 rs2297518 and $C Y B A$ rs4673), although these genes are involved in inflammatory pathways $(5,16,42)$. Few previous studies have investigated these polymorphisms. To the best of our knowledge, currently only one previous study has demonstrated the null association between IL8 rs4073 and lung cancer risk in Central and Eastern European populations (43). A significant association between lung cancer risk and $N F \kappa B$ rs28362491 was revealed in Chinese (OR for the II+ID genotypes combined vs. the DD genotype $=2.01 ; 95 \% \mathrm{CI}=1.47-2.76)(44)$ and Turkish (OR for the $\mathrm{DD}$ genotype vs. the II genotype $=3.50 ; 95 \% \mathrm{CI}=1.24-9.87)(45)$ populations, although there were conflicting results. The present study did not reproduce this significant association. To the best of our knowledge, the present study is the first case-control study on the association between NOS2 rs2297518 and CYBA rs4673 polymorphisms and lung cancer susceptibility.

The present study also demonstrated a significant additive association between $C Y B A$ rs4673 and smoking on lung cancer risk $(\mathrm{AP}=0.50 ; 95 \% \mathrm{CI}=0.15-0.85 ; \mathrm{SI}=2.66$; 95\% CI=1.01-6.99), although no significant association was 
Table II. Association between inflammation-associated polymorphisms and risk of lung cancer.

\begin{tabular}{|c|c|c|c|c|c|}
\hline \multirow[b]{2}{*}{ Polymorphism } & \multirow{2}{*}{$\begin{array}{c}\text { No. } \\
\text { cases/controls }\end{array}$} & \multirow{2}{*}{$\begin{array}{c}\text { MAF among } \\
\text { controls }\end{array}$} & \multicolumn{2}{|c|}{ OR $(95 \% \mathrm{CI})$} & \multirow[b]{2}{*}{$\mathrm{P}$-value } \\
\hline & & & Crude & Adjusted $^{\mathrm{b}}$ & \\
\hline IL8 rs4073 & & 0.32 & & & 0.94 \\
\hline $\mathrm{TT}$ & $219 / 178$ & & 1.0 (reference) & 1.0 (reference) & \\
\hline $\mathrm{TA}$ & $194 / 163$ & & $0.97(0.73-1.23)$ & $1.02(0.73-1.41)$ & \\
\hline AA & $49 / 38$ & & $1.05(0.66-1.67)$ & $1.01(0.59-1.73)$ & \\
\hline $\mathrm{TA}+\mathrm{AA}$ vs. TT & & & $0.98(0.75-1.23)$ & $1.01(0.74-1.39)$ & \\
\hline$N F \kappa B$ rs28362491 & & 0.38 & & & 0.83 \\
\hline $\mathrm{DD}$ & $48 / 53$ & & 1.0 (reference) & 1.0 (reference) & \\
\hline ID & $196 / 180$ & & $1.20(0.77-1.87)$ & $1.15(0.69-1.91)$ & \\
\hline II & $218 / 146$ & & $1.65^{\mathrm{a}}(1.06-2.57)^{\mathrm{a}}$ & $1.52(0.91-2.53)$ & \\
\hline ID+II vs. DD & & & $1.40(0.92-2.12)$ & $1.31(0.81-2.13)$ & \\
\hline NOS2 rs2297518 & & 0.07 & & & 0.95 \\
\hline $\mathrm{CC}$ & $392 / 327$ & & 1.0 (reference) & 1.0 (reference) & \\
\hline $\mathrm{CT}$ & $67 / 50$ & & $1.12(0.75-1.66)$ & $1.17(0.74-1.83)$ & \\
\hline TT & $3 / 2$ & & $1.25(0.21-7.53)$ & $2.10(0.26-17.2)$ & \\
\hline $\mathrm{CT}+\mathrm{TT}$ vs. $\mathrm{CC}$ & & & $1.12(0.76-1.65)$ & $1.19(0.76-1.86)$ & \\
\hline CYBA rs4673 & & 0.07 & & & 0.40 \\
\hline $\mathrm{CC}$ & $395 / 328$ & & 1.0 (reference) & 1.0 (reference) & \\
\hline $\mathrm{CT}$ & $62 / 48$ & & $1.07(0.72-1.61)$ & $1.10(0.69-1.76)$ & \\
\hline TT & $5 / 3$ & & $1.38(0.33-5.83)$ & $1.47(0.31-6.84)$ & \\
\hline CT+TT vs. CC & & & $1.09(0.74-1.61)$ & $1.12(0.72-1.77)$ & \\
\hline NQO1 rs 1800566 & & 0.42 & & & 0.32 \\
\hline $\mathrm{CC}$ & $122 / 133$ & & 1.0 (reference) & 1.0 (reference) & \\
\hline $\mathrm{CT}$ & $234 / 175$ & & $1.46^{\mathrm{a}}(1.06-2.00)^{\mathrm{a}}$ & $1.29(0.90-1.86)$ & \\
\hline TT & $106 / 71$ & & $1.63^{\mathrm{a}}(1.10-2.40)^{\mathrm{a}}$ & $1.78^{\mathrm{a}}(1.14-2.79)^{\mathrm{a}}$ & \\
\hline $\mathrm{CT}+\mathrm{TT}$ vs. $\mathrm{CC}$ & & & $1.51 \mathrm{a}(1.12-2.02)^{\mathrm{a}}$ & $1.42^{\mathrm{a}}(1.01-2.01)^{\mathrm{a}}$ & \\
\hline
\end{tabular}

${ }^{\mathrm{a}} \mathrm{P}<0.05 .{ }^{\mathrm{b}}$ Adjusted for age, gender, smoking status, alcohol consumption and education. ${ }^{\mathrm{c}} \mathrm{P}$ for Hardy-Weinberg equilibrium test among controls. MAF, minor allele frequency; OR, odds ratio; CI, confidence interval; IL8, interleukin 8; NFkB, nuclear factor kappa B; NOS2, Nitric oxide synthase 2; CYBA, Cytochrome b-245 alpha subunit; NQO1, NAD(P)H dehydrogenase quinone 1; DD, deletion/deletion; ID, insertion/deletion; II, insertion/insertion.

identified between rs4673 alone and the risk of disease. The present study also revealed that smoking may modify the association between $C Y B A$ rs4673 and lung cancer risk. The estimated value of the adjusted AP was $\sim 0.50$, indicating that $50 \%$ of the excess risk for lung cancer in ever-smokers with the rs4673 genotype was due to an additive association. The estimated adjusted SI value was 2.66, indicating that the risk of lung cancer in smokers with $\geq 1 \mathrm{C}$ allele was 2.66 times greater than the sum of the risks in subjects exposed to a single risk factor alone. Previous studies demonstrated that the main source of cigarette smoke-induced ROS is NOX $(46,47)$. NOX and its subunit p22phox, encoded by $C Y B A$, serves an important role in tobacco-associated oxidative stress conditions, in which carcinogenesis is promoted (15). Therefore, it has been hypothesized that the association between $C Y B A$ rs4673 and lung cancer risk becomes clearer when modified by cigarette smoking.

A previous study demonstrated that $C R P$ rs2794520 was significantly associated with an increased lung cancer risk (OR for the CT and CC genotypes combined vs. the TT genotype $=1.64$; $95 \% \mathrm{CI}=1.19-2.26)(25)$. In a previous meta-analysis, elevated levels of circulating CRP were associated with an increased risk of lung cancer (48). This suggests that the CRP level may be a potential marker of increased cancer risk. CRP reduction is associated with the minor allele (T) of rs2794520 (49); therefore, the C allele of rs2794520 may be associated with an increased risk of lung cancer. From this perspective, the interaction between CRP rs2794520, and other genetic polymorphisms, on the association of lung cancer risk were investigated; a significant additive interaction between $C R P$ rs2794520 and $C Y B A$ rs4673 (AP $=0.50 ; 95 \%$ $\mathrm{CI}=0.10-0.89 ; \mathrm{P}_{\text {interaction }}=0.048$ ) was identified. However, this must be interpreted with caution due to the limited number of cases and controls in the present study.

The present study has several limitations. Due to the small sample size, chance may not be excluded as an explanation for the significant associations observed. Case-control studies tend to be susceptible to selection bias, particularly in the 
Table III. Interaction between inflammation-associated polymorphisms and cigarette smoking.

OR $(95 \% \mathrm{CI})$

\begin{tabular}{|c|c|c|c|}
\hline \multirow{2}{*}{ Polymorphism } & \multirow[b]{2}{*}{ Smoking $^{\mathrm{b}}$} & \\
\hline & & Crude & Adjusted $^{\mathrm{c}}$ \\
\hline \multicolumn{4}{|l|}{ IL8 rs4073 } \\
\hline TT & Never & 1.0 (reference) & 1.0 (reference) \\
\hline $\mathrm{TA}+\mathrm{AA}$ & Never & $0.85(0.56-1.29)$ & $0.76(0.481 .22)$ \\
\hline $\mathrm{TT}$ & Ever & $2.09^{\mathrm{a}}(1.39-3.13)^{\mathrm{a}}$ & $2.42^{\mathrm{a}}(1.52-3.84)^{\mathrm{a}}$ \\
\hline $\mathrm{TA}+\mathrm{AA}$ & Ever & $2.47^{\mathrm{a}}(1.64-3.71)^{\mathrm{a}}$ & $3.10^{\mathrm{a}}(1.94-4.94)^{\mathrm{a}}$ \\
\hline Multiplicative interaction & & $1.39(0.79-2.44)$ & $1.68(0.89-3.17)$ \\
\hline RERI & & $0.53(-0.87-1.93)$ & $0.92(-0.29-2.13)$ \\
\hline $\mathrm{AP}$ & & $0.22(-0.34-0.77)$ & $0.30(-0.05-0.64)$ \\
\hline SI & & $1.57(0.37-6.69)$ & $1.78(0.73-4.33)$ \\
\hline \multicolumn{4}{|l|}{$N F \kappa B$ rs28362491 } \\
\hline DD & Never & 1.0 (reference) & 1.0 (reference) \\
\hline ID+II & Never & $1.11(0.61-2.05)$ & $0.99(0.50-1.98)$ \\
\hline DD & Ever & $1.83(0.83-4.02)$ & $1.97(0.81-4.82)$ \\
\hline ID+II & Ever & $2.87^{\mathrm{a}}(1.57-5.22)^{\mathrm{a}}$ & $3.34^{\mathrm{a}}(1.68-6.65)^{\mathrm{a}}$ \\
\hline Multiplicative interaction & & $1.41(0.61-3.28)$ & $1.71(0.66-4.43)$ \\
\hline RERI & & $0.93(-0.26-2.11)$ & $1.31(-0.13-2.74)$ \\
\hline $\mathrm{AP}$ & & $0.32(-0.11-0.76)$ & $0.40(-0.04-0.84)$ \\
\hline SI & & $1.99(0.46-8.52)$ & $2.36(0.44-12.5)$ \\
\hline \multicolumn{4}{|l|}{ NOS2 rs2297518 } \\
\hline $\mathrm{CC}$ & Never & 1.0 (reference) & 1.0 (reference) \\
\hline $\mathrm{CT}+\mathrm{TT}$ & Never & $1.03(0.58-1.83)$ & $1.13(0.59-2.17)$ \\
\hline $\mathrm{CC}$ & Ever & $2.41^{\mathrm{a}}(1.78-3.26)^{\mathrm{a}}$ & $3.13^{\mathrm{a}}(2.20-4.45)^{\mathrm{a}}$ \\
\hline $\mathrm{CT}+\mathrm{TT}$ & Ever & $3.16^{\mathrm{a}}(1.78-5.59)^{\mathrm{a}}$ & $3.92^{\mathrm{a}}(2.08-7.41)^{\mathrm{a}}$ \\
\hline Multiplicative interaction & & $1.27(0.57-2.85)$ & $1.11(0.45-2.72)$ \\
\hline RERI & & $0.72(-1.09-2.53)$ & $0.73(-1.61-3.07)$ \\
\hline AP & & $0.23(-0.24-0.70)$ & $0.20(-0.33-0.72)$ \\
\hline SI & & $1.50(0.58-3.86)$ & $1.36(0.55-3.38)$ \\
\hline \multicolumn{4}{|l|}{ CYBA rs 4673} \\
\hline $\mathrm{CC}$ & Never & 1.0 (reference) & 1.0 (reference) \\
\hline $\mathrm{CT}+\mathrm{TT}$ & Never & $0.88(0.49-1.60)$ & $0.70(0.36-1.36)$ \\
\hline $\mathrm{CC}$ & Ever & $2.34^{\mathrm{a}}(1.73-3.16)^{\mathrm{a}}$ & $2.80^{\mathrm{a}}(1.97-3.97)^{\mathrm{a}}$ \\
\hline $\mathrm{CT}+\mathrm{TT}$ & Ever & $3.25^{\mathrm{a}}(1.82-5.80)^{\mathrm{a}}$ & $4.98^{\mathrm{a}}(2.53-9.81)^{\mathrm{a}}$ \\
\hline Multiplicative interaction & & $1.58(0.69-3.60)$ & $2.55(0.99-6.50)$ \\
\hline RERI & & $1.03(-0.83-2.89)$ & $2.48(-0.73-5.70)$ \\
\hline $\mathrm{AP}$ & & $0.32(-0.11-0.74)$ & $0.50(0.15-0.85)^{\mathrm{d}}$ \\
\hline SI & & $1.85(0.69-4.97)$ & $2.66(1.01-6.99)^{\mathrm{e}}$ \\
\hline \multicolumn{4}{|l|}{ NQO1 rs1800566 } \\
\hline $\mathrm{CC}$ & Never & 1.0 (reference) & 1.0 (reference) \\
\hline $\mathrm{CT}+\mathrm{TT}$ & Never & $1.49(0.96-2.31)$ & $1.43(0.88-2.35)$ \\
\hline $\mathrm{CC}$ & Ever & $2.65^{\mathrm{a}}(1.60-4.39)^{\mathrm{a}}$ & $3.10^{\mathrm{a}}(1.75-5.49)^{\mathrm{a}}$ \\
\hline $\mathrm{CT}+\mathrm{TT}$ & Ever & $3.44^{\mathrm{a}}(2.26-5.24)^{\mathrm{a}}$ & $4.37^{\mathrm{a}}(2.72-7.02)^{\mathrm{a}}$ \\
\hline Multiplicative interaction & & $0.88(0.48-1.61)$ & $0.98(0.50-1.95)$ \\
\hline RERI & & $0.31(-0.99-1.61)$ & $0.84(-0.88-2.56)$ \\
\hline $\mathrm{AP}$ & & $0.09(-0.28-0.46)$ & $0.19(-0.18-0.57)$ \\
\hline SI & & $1.15(0.63-2.09)$ & $1.33(0.70-2.54)$ \\
\hline
\end{tabular}

${ }^{\mathrm{a}} \mathrm{P}<0.05 .{ }^{\mathrm{b}} \mathrm{Current}$ and former smokers were combined (ever-smokers). ${ }^{\mathrm{c}}$ Adjusted for age, gender, alcohol consumption and education. ${ }^{\mathrm{d}} \mathrm{P}_{\text {interac- }}$ tion $=0.005 ;{ }^{e} \mathrm{P}_{\text {interaction }}=0.047$. RERI, relative excess risk due to interaction; AP, attributable proportion due to interaction; SI, synergy index; OR, odds ratio; $\mathrm{CI}$, confidence interval; IL8, interleukin 8; NFאB, nuclear factor kappa B; NOS2, nitric oxide synthase 2; CYBA, Cytochrome b-245 alpha subunit; NQO1, NAD(P)H dehydrogenase quinone 1. 
Table IV. Interaction between inflammation-associated polymorphisms and CRP rs2794520.

\begin{tabular}{|c|c|c|c|}
\hline \multirow[b]{2}{*}{ Polymorphism } & \multirow[b]{2}{*}{$C R P$ rs2794520 genotype } & \multicolumn{2}{|c|}{ OR $(95 \% \mathrm{CI})$} \\
\hline & & Crude & Adjusted $^{\mathrm{b}}$ \\
\hline \multicolumn{4}{|l|}{ IL8 rs4073 } \\
\hline TT & $\mathrm{CC}$ & 1.0 (reference) & 1.0 (reference) \\
\hline $\mathrm{TA}+\mathrm{AA}$ & $\mathrm{CC}$ & $1.20(0.80-1.79)$ & $1.21(0.75-1.93)$ \\
\hline $\mathrm{TT}$ & $\mathrm{CT}+\mathrm{TT}$ & $1.73^{\mathrm{a}}(1.16-2.58)^{\mathrm{a}}$ & $1.96^{\mathrm{a}}(1.23-3.11)^{\mathrm{a}}$ \\
\hline $\mathrm{TA}+\mathrm{AA}$ & $\mathrm{CT}+\mathrm{TT}$ & $1.43^{\mathrm{a}}(0.97-2.10)^{\mathrm{a}}$ & $1.69^{\mathrm{a}}(1.08-2.64)^{\mathrm{a}}$ \\
\hline Multiplicative interaction & & $0.69(0.40-1.19)$ & $0.71(0.38-1.35)$ \\
\hline RERI & & $-0.50(-1.31-0.31)$ & $-0.47(-1.49-0.54)$ \\
\hline $\mathrm{AP}$ & & $-0.35(-0.92-0.22)$ & $-0.28(-0.89-0.32)$ \\
\hline SI & & $0.46(0.16-1.32)$ & $0.59(0.23-1.54)$ \\
\hline \multicolumn{4}{|l|}{$N F \kappa B$ rs 28362491} \\
\hline DD & $\mathrm{CC}$ & 1.0 (reference) & 1.0 (reference) \\
\hline ID+II & $\mathrm{CC}$ & $1.50(0.80-2.80)$ & $1.57(0.77-3.22)$ \\
\hline DD & $\mathrm{CT}+\mathrm{TT}$ & $1.58(0.72-3.49)$ & $2.20(0.88-5.48)$ \\
\hline ID+II & $\mathrm{CT}+\mathrm{TT}$ & $2.10^{\mathrm{a}}(1.13-3.90)^{\mathrm{a}}$ & $2.48^{\mathrm{a}}(1.21-5.06)^{\mathrm{a}}$ \\
\hline Multiplicative interaction & & $0.88(0.38-2.05)$ & $0.72(0.27-1.90)$ \\
\hline RERI & & $0.02(-1.13-1.16)$ & $-0.29(-2.04-1.46)$ \\
\hline $\mathrm{AP}$ & & $0.01(-0.54-0.56)$ & $-0.12(-0.80-0.56)$ \\
\hline SI & & $1.02(0.35-2.94)$ & $0.84(0.33-2.13)$ \\
\hline \multicolumn{4}{|l|}{ NOS2 rs 2297518} \\
\hline $\mathrm{CC}$ & $\mathrm{CC}$ & 1.0 (reference) & 1.0 (reference) \\
\hline $\mathrm{CT}+\mathrm{TT}$ & $\mathrm{CC}$ & $1.18(0.66-2.11)$ & $0.91(0.47-1.75)$ \\
\hline $\mathrm{CC}$ & $\mathrm{CT}+\mathrm{TT}$ & $1.44^{\mathrm{a}}(1.07-1.93)^{\mathrm{a}}$ & $1.53^{\mathrm{a}}(1.08-2.16)^{\mathrm{a}}$ \\
\hline $\mathrm{CT}+\mathrm{TT}$ & $\mathrm{CT}+\mathrm{TT}$ & $1.55(0.91-2.63)$ & $2.31^{\mathrm{a}}(1.23-4.34)^{\mathrm{a}}$ \\
\hline Multiplicative interaction & & $0.91(0.42-1.98)$ & $1.67(0.67-4.13)$ \\
\hline RERI & & $-0.08(-1.13-0.97)$ & $0.88(-1.07-2.83)$ \\
\hline $\mathrm{AP}$ & & $-0.05(-0.74-0.65)$ & $0.38(-0.34-1.10)$ \\
\hline SI & & $0.88(0.15-5.29)$ & $3.01(0.09-105)$ \\
\hline \multicolumn{4}{|l|}{$C Y B A$ rs 4673} \\
\hline $\mathrm{CC}$ & $\mathrm{CC}$ & 1.0 (reference) & 1.0 (reference) \\
\hline $\mathrm{CT}+\mathrm{TT}$ & $\mathrm{CC}$ & $0.75(0.41-1.37)$ & $0.72(0.37-1.43)$ \\
\hline $\mathrm{CC}$ & $\mathrm{CT}+\mathrm{TT}$ & $1.30(0.97-1.74)$ & $1.47^{\mathrm{a}}(1.04-2.07)^{\mathrm{a}}$ \\
\hline $\mathrm{CT}+\mathrm{TT}$ & $\mathrm{CT}+\mathrm{TT}$ & $1.87^{\mathrm{a}}(1.08-3.24)^{\mathrm{a}}$ & $2.38^{\mathrm{a}}(1.25-4.51)^{\mathrm{a}}$ \\
\hline Multiplicative interaction & & $1.91(0.85-4.29)$ & $2.23(0.88-5.65)$ \\
\hline RERI & & $0.82(-0.24-1.89)$ & $1.18(-0.32-2.69)$ \\
\hline $\mathrm{AP}$ & & $0.44^{\mathrm{a}}(0.04-0.84)^{\mathrm{a}}$ & $0.50(0.10-0.89)^{\mathrm{a}}$ \\
\hline SI & & $16.5(0.00-\infty)$ & $7.08(0.14-366)$ \\
\hline \multicolumn{4}{|l|}{ NQO1 rs1800566 } \\
\hline $\mathrm{CC}$ & $\mathrm{CC}$ & 1.0 (reference) & 1.0 (reference) \\
\hline $\mathrm{CT}+\mathrm{TT}$ & $\mathrm{CC}$ & $1.57^{\mathrm{a}}(1.01-2.43)^{\mathrm{a}}$ & $1.57(0.94-2.62)$ \\
\hline $\mathrm{CC}$ & $\mathrm{CT}+\mathrm{TT}$ & $1.50(0.91-2.46)$ & $1.86^{\mathrm{a}}(1.04-3.31)^{\mathrm{a}}$ \\
\hline $\mathrm{CT}+\mathrm{TT}$ & $\mathrm{CT}+\mathrm{TT}$ & $2.15^{\mathrm{a}}(1.41-3.29)^{\mathrm{a}}$ & $2.44^{\mathrm{a}}(1.48-4.03)^{\mathrm{a}}$ \\
\hline Multiplicative interaction & & $0.91(0.50-1.66)$ & $0.84(0.42-1.68)$ \\
\hline RERI & & $0.08(-0.78-0.94)$ & $0.29(-0.69-1.27)$ \\
\hline AP & & $0.04(-0.36-0.44)$ & $0.12(-0.29-0.53)$ \\
\hline SI & & $1.08(0.48-2.42)$ & $1.01(0.46-2.24)$ \\
\hline
\end{tabular}

${ }^{\mathrm{a}} \mathrm{P}<0.05$. ${ }^{\mathrm{b}}$ Adjusted for age, gender, smoking status, alcohol consumption, and education. RERI, relative excess risk due to interaction; AP, attributable proportion due to interaction; SI, synergy index; OR, odds ratio; CI, confidence interval; IL8, interleukin 8; NFkB, nuclear factor kappa B; NOS2, nitric oxide synthase 2; CYBA, Cytochrome b-245 alpha subunit; NQO1, NAD(P)H dehydrogenase quinone 1; CRP, C-reactive protein. 
control group. Controls may, therefore, represent the source population from which the cases were drawn. However, when using hospital-based patients (hospital controls), it may not be possible to define the population from which the cases are drawn. If the study population may be defined as potential hospital users, hospital controls may be more appropriate (50). Generally, the reported rates of participation are slightly higher in hospital-based, compared with population-based, case-control studies and a high participation rate may reduce the possibility of selection bias (51). In the present study, participation rates of cases and controls were high. However, due to the possibility of selection bias the results must be interpreted with caution in case-control studies. The current study's sample size may prevent any conclusive inference, thus replication of the findings in studies with larger sample sizes is important prior to any causal inference being drawn.

In conclusion, the TT genotype of NQO1 rs1800566 was significantly associated with an increased risk of lung cancer, and a significant additive interaction between $C Y B A$ rs 4673 and smoking was revealed. Findings from polymorphism-environment or polymorphism-polymorphism association analyses must be interpreted with caution due to reduced numbers of observations in the subgroups. Therefore, the replication of these analyses in various populations is an important prospective step. Future studies involving larger control and case populations are warranted in order to corroborate the association among the Japanese cases presented in the current study.

\section{Acknowledgements}

The present study was supported by a Grant-in-Aid for Scientific Research (grant no. 25293143) from the Ministry of Education, Culture, Sports, Science and Technology (Japan).

\section{References}

1. Alberg AJ, Ford JG and Samet JM; American College of Chest Physicians: Epidemiology of lung cancer: ACCP evidence-based clinical practice guidelines (2nd edition). Chest 132 (3 Suppl) 29S-55S, 2007.

2. Villeneuve PJ and Mao Y: Lifetime probability of developing lung cancer, by smoking status, Canada. Can J Public Health 85: 385-388, 1994

3. Zhang R, Chu M, Zhao Y, Wu C, Guo H, Shi Y, Dai J, Wei Y, Jin $\mathrm{G}, \mathrm{Ma} \mathrm{H}$, et al: A genome-wide gene-environment interaction analysis for tobacco smoke and lung cancer susceptibility. Carcinogenesis 35: 1528-1535, 2014.

4. Coussens LM and Werb Z: Inflammation and cancer. Nature 420: 860-867, 2002

5. Kamp DW, Shacter E and Weitzman SA: Chronic inflammation and cancer: The role of the mitochondria. Oncology (Williston Park) 25: 400-410, 413, 2011.

6. Grivennikov SI and Karin M: Inflammation and oncogenesis: A vicious connection. Curr Opin Genet Dev 20: 65-71, 2010.

7. Takizawa H, Tanaka M, Takami K, Ohtoshi T, Ito K, Satoh M, Okada Y, Yamasawa F and Umeda A: Increased expression of inflammatory mediators in small-airway epithelium from tobacco smokers. Am J Physiol Lung Cell Mol Physiol 278 : L906-L913, 2000.

8. Xie K: Interleukin-8 and human cancer biology. Cytokine Growth Factor Rev 12: 375-391, 2001.

9. Masuya D, Huang C, Liu D, Kameyama K, Hayashi E, Yamauchi A, Kobayashi S, Haba R and Yokomise H: The intratumoral expression of vascular endothelial growth factor and interleukin-8 associated with angiogenesis in nonsmall cell lung carcinoma patients. Cancer 92: 2628-2638, 2001.

10. Grivennikov SI, Greten FR and Karin M: Immunity, inflammation, and cancer. Cell 140: 883-899, 2010.
11. Huang D, Yang L, Liu Y, Zhou Y, Guo Y, Pan M, Wang Y, Tan Y, Zhong H, Hu M, et al: Functional polymorphisms in NFkB1/IkBa predict risks of chronic obstructive pulmonary disease and lung cancer in Chinese. Hum Genet 132: 451-460, 2013.

12. Tang X, Liu D, Shishodia S, Ozburn N, Behrens C, Lee JJ, Hong WK, Aggarwal BB and Wistuba II: Nuclear factor-kappaB (NF-kappaB) is frequently expressed in lung cancer and preneoplastic lesions. Cancer 107: 2637-2646, 2006.

13. Lambeth JD: Nox enzymes, ROS, and chronic disease: An example of antagonistic pleiotropy. Free Radic Biol Med 43: 332-347, 2007.

14. Bedard K, Attar H, Bonnefont J, Jaquet V, Borel C, Plastre O, Stasia MJ, Antonarakis SE and Krause KH: Three common polymorphisms in the CYBA gene form a haplotype associated with decreased ROS generation. Hum Mutat 30: 1123-1133, 2009.

15. Ushio-Fukai M and Nakamura Y: Reactive oxygen species and angiogenesis: NADPH oxidase as target for cancer therapy. Cancer Lett 266: 37-52, 2008.

16. Hussain SP, Hofseth LJ and Harris CC: Radical causes of cancer. Nat Rev Cancer 3: 276-285, 2003.

17. Ross D, Kepa JK, Winski SL, Beall HD, Anwar A and Siegel D: NAD(P)H: Quinone oxidoreductase 1 (NQO1): Chemoprotection, bioactivation, gene regulation and genetic polymorphisms. Chem Biol Interact 129: 77-97, 2000.

18. Joseph P and Jaiswal AK: NAD(P)H: Quinone oxidoreductase1 (DT diaphorase) specifically prevents the formation of benzo[a] pyrene quinone-DNA adducts generated by cytochrome P4501A1 and P450 reductase. Proc Natl Acad Sci USA 91: 8413-8417, 1994.

19. De Flora S, Bennicelli C, D'Agostini F, Izzotti A and Camoirano A: Cytosolic activation of aromatic and heterocyclic amines. Inhibition by dicoumarol and enhancement in viral hepatitis B. Environ Health Perspect 102 (Suppl 6): S69-S74, 1994.

20. Eom SY, Zhang YW, Kim SH, Choe KH, Lee KY, Park JD, Hong YC, Kim YD, Kang JW and Kim H: Influence of NQO1, ALDH2, and CYP2E1 genetic polymorphisms, smoking, and alcohol drinking on the risk of lung cancer in Koreans. Cancer Causes Control 20: 137-145, 2009.

21. Dinkova-Kostova AT and Talalay P: NAD(P)H:quinone acceptor oxidoreductase 1 (NQO1), a multifunctional antioxidant enzyme and exceptionally versatile cytoprotector. Arch Biochem Biophys 501: 116-123, 2010.

22. Meyer ML, Potts-Kant EN, Ghio AJ, Fischer BM, Foster WM and Voynow JA: NAD $(\mathrm{P}) \mathrm{H}$ quinone oxidoreductase 1 regulates neutrophil elastase-induced mucous cell metaplasia. Am J Physiol Lung Cell Mol Physiol 303: L181-L188, 2012.

23. Engels EA, Wu X, Gu J, Dong Q, Liu J and Spitz MR: Systematic evaluation of genetic variants in the inflammation pathway and risk of lung cancer. Cancer Res 67: 6520-6527, 2007.

24. Engels EA: Inflammation in the development of lung cancer: Epidemiological evidence. Expert Rev Anticancer Ther 8: 605-615, 2008

25. Kiyohara C, Horiuchi T, Takayama K and Nakanishi Y: Genetic polymorphisms involved in the inflammatory response and lung cancer risk: A case-control study in Japan. Cytokine 65: 88-94, 2014.

26. Chaturvedi AK, Caporaso NE, Katki HA, Wong HL, Chatterjee N, Pine SR, Chanock SJ, Goedert JJ and Engels EA: $\mathrm{C}$-reactive protein and risk of lung cancer. J Clin Oncol 28: 2719-2726, 2010

27. Senol Tuncay S, Okyay P and Bardakci F: Identification of NF-kappaB1 and NF-kappaBIAlpha polymorphisms using PCR-RFLP assay in a Turkish population. Biochem Genet 48: 104-112, 2010.

28. Johnson VJ, Yucesoy B and Luster MI: Genotyping of single nucleotide polymorphisms in cytokine genes using real-time PCR allelic discrimination technology. Cytokine 27: 135-141, 2004.

29. http://www.kenkounippon21.gr.jp/kenkounippon21/about/ kakuron/index.html

30. Andersson T, Alfredsson L, Källberg H, Zdravkovic S and Ahlbom A: Calculating measures of biological interaction. Eur J Epidemiol 20: 575-579, 2005.

31. Peng WJ, He Q, Yang JX, Wang BX, Lu MM, Wang S and Wang J: Meta-analysis of association between cytokine gene polymorphisms and lung cancer risk. Mol Biol Rep 39: 5187-5194, 2012.

32. Taguchi A, Ohmiya N, Shirai K, Mabuchi N, Itoh A, Hirooka Y, Niwa $\mathrm{Y}$ and Goto $\mathrm{H}$ : Interleukin-8 promoter polymorphism increases the risk of atrophic gastritis and gastric cancer in Japan. Cancer Epidemiol Biomarkers Prev 14: 2487-2493, 2005. 
33. Sugimoto Y, Wakai K, Nakagawa H, Suma S, Sasakabe T, Sakamoto T, Takashima N, Suzuki S, Ogawa S, Ohnaka K, et al: Associations between polymorphisms of interleukin-6 and related cytokine genes and serum liver damage markers: A cross-sectional study in the Japan multi-institutional collaborative cohort (J-MICC) study. Gene 557: 158-162, 2015.

34. Shirai K, Ohmiya N, Taguchi A, Mabuchi N, Yatsuya H, Itoh A, Hirooka Y, Niwa Y, Mori N and Goto H: Interleukin-8 gene polymorphism associated with susceptibility to non-cardia gastric carcinoma with microsatellite instability. J Gastroenterol Hepatol 21: 1129-1135, 2006.

35. Lou Y, Li R, Xiong L, Gu A, Shi C, Chu T, Zhang X, Gu P, Zhong $\mathrm{H}$, Wen $\mathrm{S}$ and Han B: NAD $(\mathrm{P}) \mathrm{H}$ : quinone oxidoreductase 1 (NQO1) C609T polymorphism and lung cancer risk: A meta-analysis. Tumour Biol 34: 3967-3979, 2013.

36. Traver RD, Siegel D, Beall HD, Phillips RM, Gibson NW, Franklin WA and Ross D: Characterization of a polymorphism in NAD(P)H: Quinone oxidoreductase (DT-diaphorase). Br J Cancer 75: 69-75, 1997.

37. Lee PN, Forey BA and Coombs KJ: Systematic review with meta-analysis of the epidemiological evidence in the 1900s relating smoking to lung cancer. BMC Cancer 12: 385, 2012.

38. Prawan A, Buranrat B, Kukongviriyapan U, Sripa B and Kukongviriyapan V: Inflammatory cytokines suppress NAD (P)H:quinone oxidoreductase- 1 and induce oxidative stress in cholangiocarcinoma cells. J Cancer Res Clin Oncol 135: 515-522, 2009.

39. Asher G, Lotem J, Cohen B, Sachs L and Shaul Y: Regulation of p53 stability and p53-dependent apoptosis by NADH quinone oxidoreductase 1. Proc Natl Acad Sci USA 98: 1188-1193, 2001.

40. Levine AJ: p53, the cellular gatekeeper for growth and division. Cell 88: 323-331, 1997.

41. Siegel D, Anwar A, Winski SL, Kepa JK, Zolman KL and Ross D: Rapid polyubiquitination and proteasomal degradation of a mutant form of $\mathrm{NAD}(\mathrm{P}) \mathrm{H}$ :quinone oxidoreductase 1 . Mol Pharmacol 59: 263-268, 2001.

42. Guzik TJ, West NE, Black E, McDonald D, Ratnatunga C, Pillai R and Channon KM: Functional effect of the $\mathrm{C} 242 \mathrm{~T}$ polymorphism in the $\mathrm{NAD}(\mathrm{P}) \mathrm{H}$ oxidase $\mathrm{p} 22$ phox gene on vascular superoxide production in atherosclerosis. Circulation 102: 1744-1747, 2000.
43. Campa D, Hung RJ, Mates D, Zaridze D, Szeszenia-Dabrowska N, Rudnai P, Lissowska J, Fabiánová E, Bencko V, Foretova L, et al: Lack of association between -251 T>A polymorphism of IL8 and lung cancer risk. Cancer Epidemiol Biomarkers Prev 14: 2457-2458, 2005.

44. Wang Y, Chen L, Pan L, Xue J and Yu H: The association between NFKB1-94ins/del ATTG polymorphism and non-small cell lung cancer risk in a Chinese Han population. Int J Clin Exp Med 8: 8153-8157, 2015

45. Oltulu YM, Coskunpinar E, Ozkan G, Aynaci E, Yildiz P, Isbir T and Yaylim I: Investigation of NF-kB1 and NF-kBIA gene polymorphism in non-small cell lung cancer. Biomed Res Int 2014: 530381, 2014

46. Orosz Z, Csiszar A, Labinskyy N, Smith K, Kaminski PM, Ferdinandy P, Wolin MS, Rivera A and Ungvari Z: Cigarette smoke-induced proinflammatory alterations in the endothelial phenotype: Role of NAD(P)H oxidase activation. Am J Physiol Heart Circ Physiol 292: H130-H139, 2007.

47. Jaimes EA, DeMaster EG, Tian RX and Raij L: Stable compounds of cigarette smoke induce endothelial superoxide anion production via NADPH oxidase activation. Arterioscler Thromb Vasc Biol 24: 1031-1036, 2004.

48. Heikkilä K, Harris R, Lowe G, Rumley A, Yarnell J, Gallacher J, Ben-Shlomo Y, Ebrahim S and Lawlor DA: Associations of circulating $\mathrm{C}$-reactive protein and interleukin- 6 with cancer risk: Findings from two prospective cohorts and a meta-analysis. Cancer Causes Control 20: 15-26, 2009.

49. Chu AY, Guilianini F, Barratt BJ, Nyberg F, Chasman DI and Ridker PM: Pharmacogenetic determinants of statin-induced reductions in C-reactive protein. Circ Cardiovasc Genet 5: 58-65, 2012.

50. dos santos Silva I: Case-control studies. In: Cancer Epidemiology: Principles and Methods. IARC Press, Lyon, pp189-212, 1999.

51. Morton LM, Cahill J and Hartge P: Reporting participation in epidemiologic studies: A survey of practice. Am J Epidemiol 163: 197-203, 2006. 